\title{
Design and Analysis of a Compact Band Notch UWB Antenna for Body Area Network
}

\author{
H. M. Arifur Rahman, Mohammad Monirujjaman Khan \\ Department of Electrical \& Computer Engineering, School of Engineering \& Physical Science, North South University, \\ Bashundhara, Dhaka \\ Email: arifurrahmanhm@gmail.com, monirujjaman.khan@northsouth.edu
}

How to cite this paper: Rahman, H.M.A. and Khan, M.M. (2018) Design and Analysis of a Compact Band Notch UWB Antenna for Body Area Network. Journal of Electromagnetic Analysis and Applications, 10, 157-169.

https://doi.org/10.4236/jemaa.2018.109012

Received: August 14, 2018

Accepted: September 17, 2018

Published: September 20, 2018

Copyright $\odot 2018$ by authors and Scientific Research Publishing Inc. This work is licensed under the Creative Commons Attribution International License (CC BY 4.0).

http://creativecommons.org/licenses/by/4.0/

\begin{abstract}
This paper presents the design of a small printed ultra wideband antenna with Band Notched characteristics. Both the free space and on-body performances of this antenna were investigated through simulation. The newly designed UWB antenna is more revised small form factor sized, with the ability to avoid interference caused by WLAN $(5.15-5.825 \mathrm{GHz})$ and WiMAX (5.25 - $5.85 \mathrm{GHz}$ ) systems with a band notch. The return loss response, gain, radiation pattern on free space of the antenna were investigated. After that, the on-body performances were tested on 3-layer human body model with radiation pattern, gain, return loss, and efficiency at 3.5, 5.7, 8, $10 \mathrm{GHz}$ and all the results were compared with free space results. As the on-body performance was very good, the proposed antenna will be suitable to be used for multi-purpose medical applications and sports performance monitoring.
\end{abstract}

\section{Keywords}

Ultra Wide Band Antenna, Small Form Factor Antenna, Body Area Networks, Band Notch, Printed Antenna, Wireless Body Area Network, Multiple Slot Antenna

\section{Introduction}

Ultra wideband communication has become one of the most popular and innovative technologies, which can be used for high speed, limited ranged data transmission. The UWB technology offers increased data rate communication links and low power emission level with increased efficiency. Moreover, designing UWB networks requires less effort and complexity, which grabs many researchers' attention in this area thus, designing Ultra wideband antennas becoming more popular day-by-day [1]. 
The basic mechanism of Ultra-wideband communications is different from other existing communication techniques. UWB networks use immensely narrow $\mathrm{RF}$ pulses to communicate within receivers and transmitters. Short duration pulses are the main building blocks, which intensely creates a wider bandwidth and includes various advantages, such as covertness, large throughput, less vulnerable to jamming, and in the meantime, coexistence with existing radio services.

Traditional Ultra Wideband antennas are mostly multi-narrowband antennas whereas, antennas are supposed to be optimized for receiving a coherent signal across their entire operating bandwidth. Moreover, an ideal Ultra Wideband antenna should be capable of operating on all frequencies between 3.1 to $10.6 \mathrm{GHz}$ at the same time. For this reason, the performance and the behavior of a UWB antenna must be consistent and its nature should be predictable throughout the entire band.

One of the major fields of Ultra Wideband communication is the body-centric wireless networks or, BCWN in short. Body-centric wireless network uses various sensors with multiple units dispersed throughout the human body to obtain necessary physiological information, as it is used in healthcare centers for monitoring patients various physical conditions [2] [3]. A human body wearable base station will be set to receive the required physical data measured and obtained by the sensors spread on the human body. However, Antennas are the key element in body-centric wireless communications. They play a significant role to optimize performance of radio signals. The range of application of Body-centric wireless networks covers from monitoring chronic disease patients and elderly care to general wellbeing observation and various sports performance analysis [2] [3] [4] [5].

In the recent few years, keeping pace with the increasing growth of interest on the UWB technology in wearable applications, researchers got attracted on researching Body-centric UWB antennas worldwide [3] [6]-[12]. Designing of UWB antennas gets more complicated for wireless body area network (WBAN) because of difficulties in predicting human body environment and in the same time miniaturization in physical dimensions. These constraints need to be taken into account while designing UWB antennas for wireless body area network.

The performance of an antenna on free space operation differs from the performance of the same antenna placed near/on the human body; as the human body acts as a lossy medium. Human body tissues' electromagnetic absorption phenomenon creates trouble into the radio signals by changing radiation patterns and efficiency, making distortions, changing antenna impedance or sometimes by shifting frequencies. Thus, body centric antennas' designing is a challenging work [7].

The FCC; Federal Communication Commission, has assigned the frequency band for Ultra Wideband from 3.1 GHz to $10.6 \mathrm{GHz}$ [13]. Meanwhile, few other signal spectrums such as, WLAN (5.15 to $5.825 \mathrm{GHz}$ ) and WiMAX (5.25 - 5.85 
$\mathrm{GHz}$ ) are making some interference within this range [14]. For this reason, the overall performance of UWB systems degrades in terms of bit error rate and creating pulse distortions [15]. Thus, it becomes mandatory to design UWB antennas with band notched characteristics in above mentioned frequency bands to ensure robust and interference free UWB antenna.

There are numerous antenna designs designed by the researchers all over the world that can qualify to achieve UWB bandwidth characteristics. Designs like Vivaldi antennas operate on UWB but its Omni-directional restrictions make them not suitable for portable or wearable indoor uses. On the same time mono-conical, bi-conical, spiral and log periodic antennas are also not suitable for wearable devices for their bulky shapes and bigger physical dimensions and dispersive behavior and ringing effect [16]. For this reason, printed monopole compact antennas are the best option for wearable devices or in different indoor uses.

Although, we notice the increasing interest in research and development in the field of designing Ultra wideband wearable antennas in the recent few years, unfortunately, there have been no dramatic development in the designing of wearable UWB antennas [9] [12]. Three different wearable microstrip UWB antennas were presented by Chen et al. while there operating frequency is lower portion (3 to $5 \mathrm{GHz}$ ) of the UWB frequency band [9]. Time-domain characteristics of an aperture-stacked body-worn UWB patch antenna were presented through numerical modelling by Klemm et al. [10]. A planar inverted cone antenna (PICA) with an omnidirectional monopole pattern shows comparatively better performances for on-body wireless communications. This was experimented with a comparison between two distinct modeled UWB antennas [17]. However, these antennas are somewhat larger in dimensions.

A perfectly designed ultra-wideband antenna can optimize hundreds of tasks in the field of medical services and entertainment, especially, when equipped in a wearable lightweight device. A miniaturized wearable electronic device with a UWB technology can serve the requirements of extremely high data transmission rate with a limited range, can connect all devices that a person caries \& cooperate them with one another. To avoid interferences with other existing networks and serve the purpose flawlessly a band notch is also mandatory. This research work has taken the inspiration from all those matters by creating a new, innovative, and effective design.

In this paper, a small printed band notched UWB antenna is proposed. The band notch has been achieved by etching multiple slots on the patch. Simulations were done on CST Microwave Studio electromagnetic simulator. The proposed antenna was studied in close proximity to the human body simulation model for on-body communications.

The rest of this paper is arranged as follows. Section II describes the antenna design and dimensions. Section III presents the performance parameters of the antenna with simulation. In Section IV, the performance of the proposed anten- 
na was investigated by simulating on a human body model and finally, Section $\mathrm{V}$ draws the conclusion of the paper.

\section{Antenna Design}

This antenna consists of three planer parts; the patch, substrate and the ground plane. The antenna is $16 \times 25 \mathrm{~mm}$ in dimension. The ground plane is made of annealed copper. It is attached to the bottom of the substrate level, which is made with FR-4 (lossy). It has a relative permittivity of, $\varepsilon_{r}=3$. The ground has a semi heart shape. On the top of the substrate, the patch antenna is attached with a feed line. A triangular narrow slot with a rectangle shape attached to it was created on the middle of the patch to achieve desired response. A waveguide port is attached for excitation source.

The feed line is $9.8 \mathrm{~mm}$ in length. The radius of the elliptical half-cylinder is $3.8 \mathrm{~mm}$ and $5.5 \mathrm{~mm}$; X \& Y radius respectively. Thickness of the patch layer is $0.07 \mathrm{~mm}$. The triangular slot is an equilateral triangle with $0.2 \mathrm{~mm}$ thickness of arms. The internal rectangle has a length of $4 \mathrm{~mm}$ and a height of $1.8 \mathrm{~mm}$ with $0.4 \mathrm{~mm}$ slots on top \& the bottom.

The substrate thickness is $1.495 \mathrm{~mm}$. The ground plane consists of three coexisting slots; a rectangular, triangular and a circular slot. Radius of the circle is $6.65 \mathrm{~mm}$ and the center is horizontally in the middle of the plane but $14.9 \mathrm{~mm}$ higher from the bottom. The rectangular slot is $11 \mathrm{~mm}$ in length and $16 \mathrm{~mm}$ in width and slotted out from top left corner. The triangular part vertices are shown in Figure 1 with coordinates for better understanding. The plane is 0.035 mm thick.

\section{Free Space Performance Parameters}

\subsection{Return Loss}

Free space simulation was done on CST Microwave Studio. Figure 2 shows the Return loss (S11) plot of the proposed antenna on free space. The antenna has a good bandwidth of 3 to $10.7 \mathrm{GHz}$ with a return loss curve under $-10 \mathrm{~dB}$, including the Band Notch covering the range of $4.42 \mathrm{GHz}$ to $6.9 \mathrm{GHz}$. This can effectively avoid interference with the existing WLAN (5.15 to $5.825 \mathrm{GHz}$ ) and WiMAX (5.25 - $5.85 \mathrm{GHz})$ systems.

On the above figure, proposed antenna's return loss curve on free space was plotted. Marker 1 and 2 were positioned on the boundaries of UWB bandwidth; 3.1 and $10.6 \mathrm{GHz}$ respectively. Marker 3 indicates most popular $2.4 \mathrm{GHz}$ wireless frequency, which is nicely cutout from the antenna's active frequency range. Marker 4 and 5 shows the notched frequencies from 5.15 to $5.85 \mathrm{GHz}$, excluded for avoiding interference with WLAN and WiMAX.

\subsection{Radiation Patterns}

Radiation pattern of the proposed UWB antenna was simulated on XY and XZ planes on $3.5,8 \& 10 \mathrm{GHz}$ respectively. 


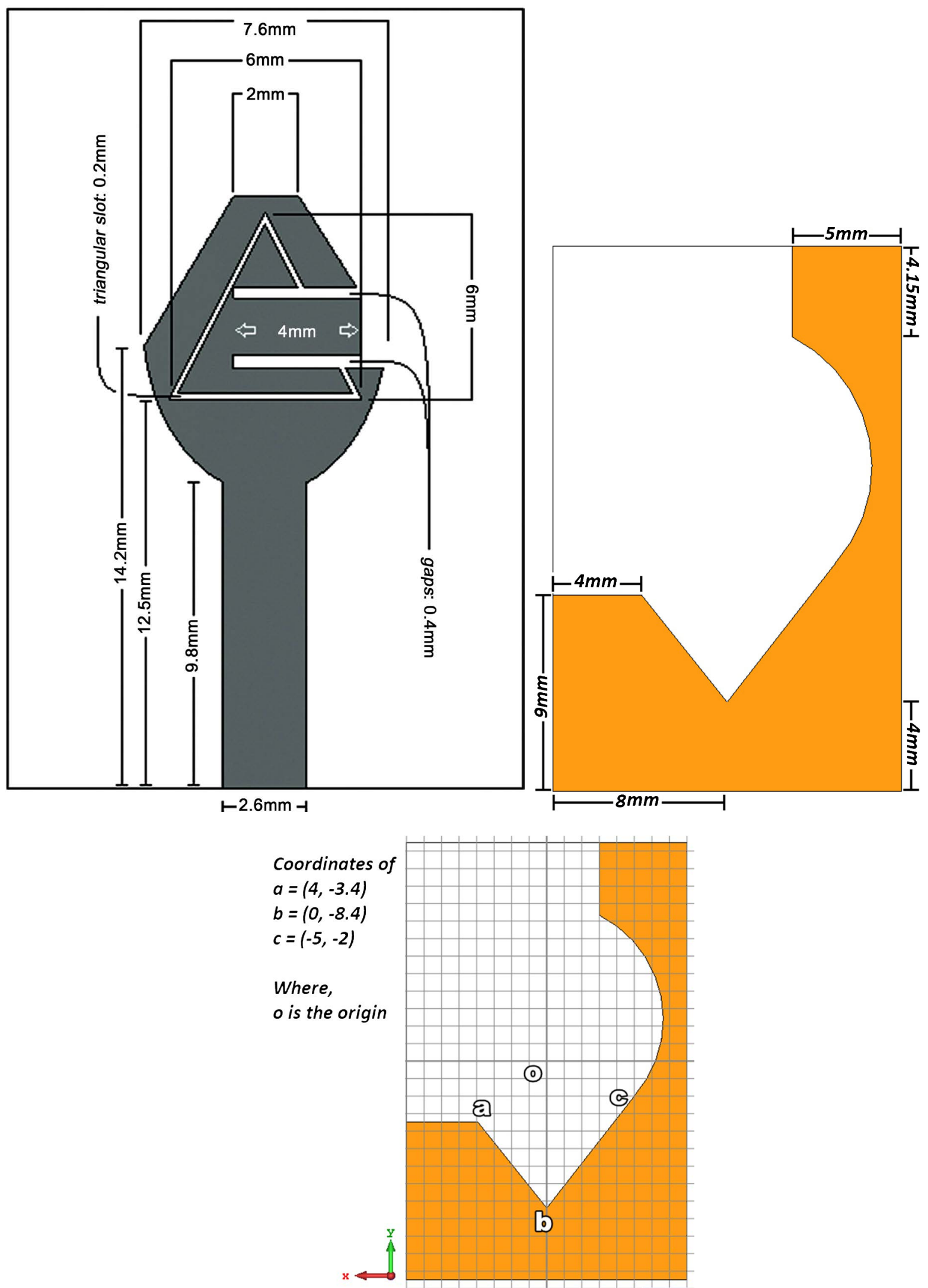

Figure 1. Antenna front \& back-patch and ground planes respectively. 
Radiation pattern on $3.5 \mathrm{GHz}$ is showed on Figure 3 where, XY plane has a main lobe magnitude of $0.219 \mathrm{~dB}$ on $190^{\circ}$ with an angular width of $96.3^{\circ}$. On XZ plane, the main lobe magnitude is $1.13 \mathrm{~dB}$ at $11^{\circ}$ with an angular width of $98.1^{\circ}$.

Figure 4 shows the radiation pattern on $8 \mathrm{GHz}$. Here, XY plane has a main lobe magnitude of $1.39 \mathrm{~dB}$ on $211^{\circ}$ with an angular width of $67.4^{\circ}$. On XZ plane, the main lobe magnitude is $2.44 \mathrm{~dB}$ at $347^{\circ}$ with an angular width of $73.8^{\circ}$.

On $10 \mathrm{GHz}$, XY plane has a main lobe magnitude of $-0.607 \mathrm{~dB}$ on $343^{\circ}$ with an angular width of $96.5^{\circ}$. On XZ plane, the main lobe magnitude is $2.69 \mathrm{~dB}$ at $21^{\circ}$ with an angular width of $83.2^{\circ}$. Figure 5 Shows the free space radiation patterns of $10 \mathrm{GHz}$ on both $\mathrm{XY}$ and $\mathrm{XZ}$ plane.

\subsection{Gain}

Simulated free space gain of the proposed antenna on $3.5,8 \& 10 \mathrm{GHz}$ are 1.168 , $2.802 \& 2.706 \mathrm{dBi}$ respectively. Table 2 shows relative comparison between free space and on-body gain on 3-layer human body model.

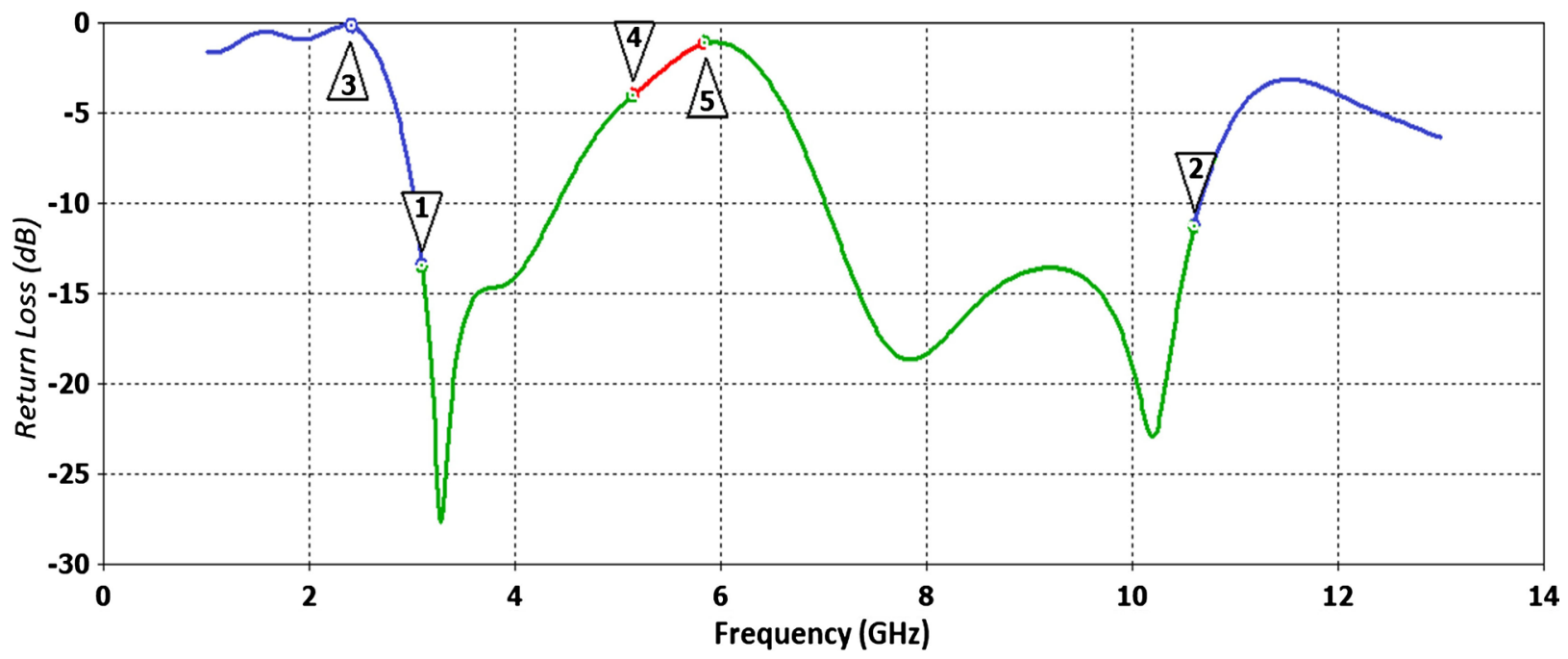

Figure 2. S11 plot of the antenna on free space.

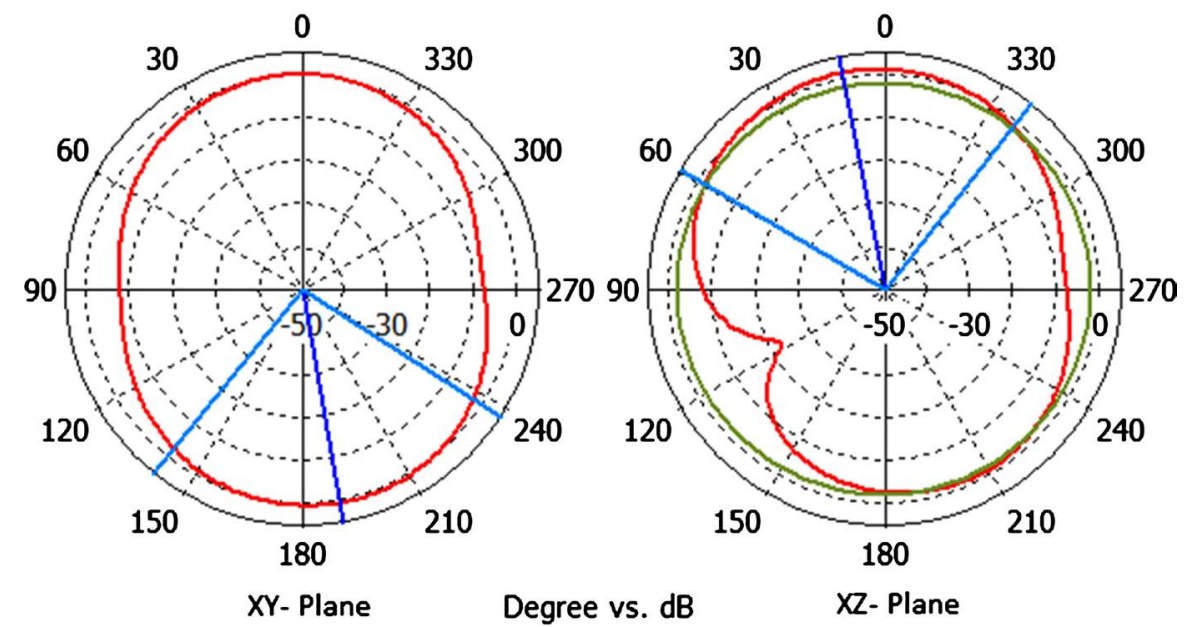

Figure 3. Radiation patterns at $3.5 \mathrm{GHz}$. 


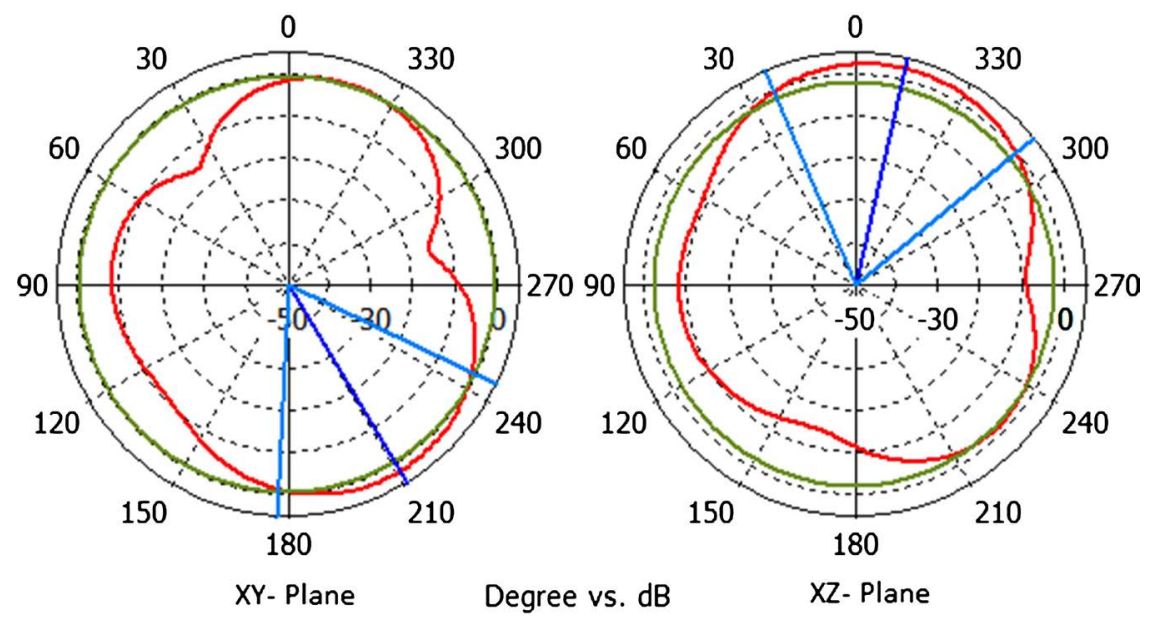

Figure 4. Radiation patterns at $8 \mathrm{GHz}$.

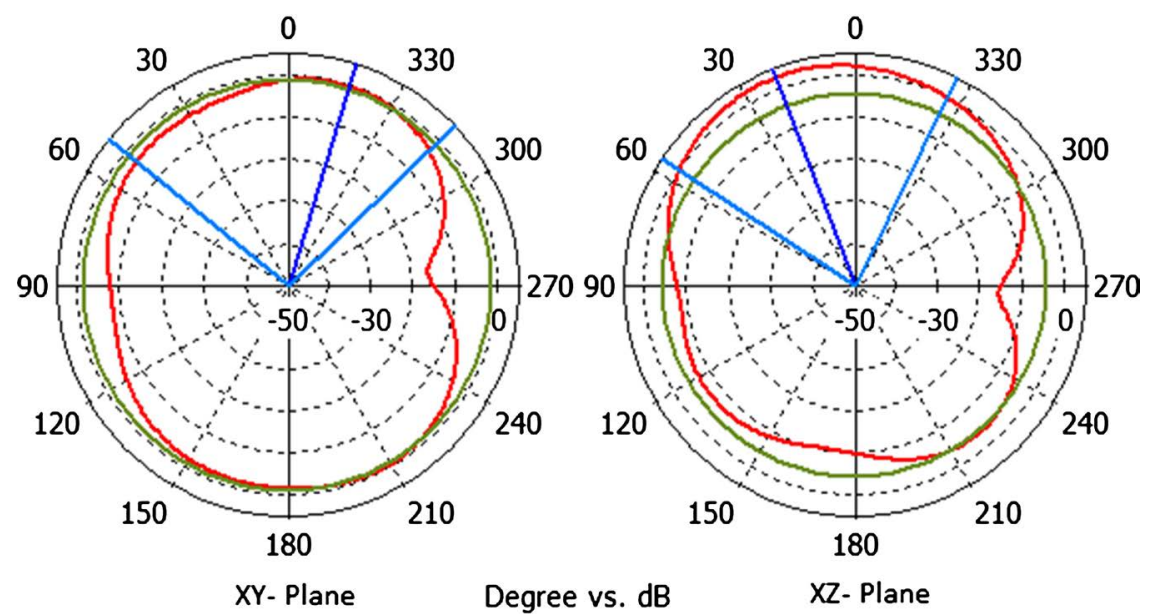

Figure 5. Radiation patterns at $10 \mathrm{GHz}$.

\section{On-Body Simulation}

For On-Body simulation, a human body model consists of three outermost layer of human body (skin, fat, and muscle) was made. The average thickness of an adult human skin is roughly around $2 \mathrm{~mm}$ [18] and fat is taken $10 \mathrm{~mm}$ [19]. With these layers, $10 \mathrm{~mm}$ depth of the muscle was taken into account. Figure 6 shows how the antenna was placed with the 3-layer human body model.

An empty space of $4 \mathrm{~mm}$ was kept between the antenna and the skin layer for on body simulation tests.

On body simulation test is divided into four sections. As the human body models elements have different electric conductivity and relative permittivity for different frequencies therefore, it required individual simulation tests for different frequency segments. The manually configured materials for human body model were created based on four different frequencies. They are, $3.5 \mathrm{GHz}, 5.7$ $\mathrm{GHz}, 8 \mathrm{GHz}$, and $9 \mathrm{GHz}$. For this reason, the full simulation was segmented into four frequency ranges; $2 \mathrm{GHz}$ to $5 \mathrm{GHz}, 5 \mathrm{GHz}$ to $7 \mathrm{GHz}, 7 \mathrm{GHz}$ to $9 \mathrm{GHz}$ and 9 $\mathrm{GHz}$ to $11 \mathrm{GHz}$ and ran simulation tests for $3.5 \mathrm{GHz}, 5.7 \mathrm{GHz}, 8 \mathrm{GHz}$, and 
$9 \mathrm{GHz}$ respectively. Finally, they were merged altogether to compare with free-space simulation test results. Table 1 shows Electric conductivity and relative permittivity of different layers on different frequencies [20].

\subsection{On-Body Return Loss Curve}

After putting the antenna above the human body model, return loss curve has changed a bit as expected; as placing an antenna next to a lossy medium like, human body, its electromagnetic absorption reduces its radiation efficiencies and some pattern distortions by such unpredictable changes in antenna impedance. Comparison between free space and on-body return loss curve is shown in Figure 7.

The entire return loss curve was slightly left shifted. However, the notched frequency band remains perfect. On the on-body simulation s11 curve, several bands on 3.2 to $3.8 \mathrm{GHz}$ and 7 to $10.5 \mathrm{GHz}$ shows better return loss response.

\subsection{On-Body Radiation Pattern}

Comparison between the radiation patterns for free space and on-body test of the proposed antenna was simulated on $3.5 \mathrm{GHz}, 5.7 \mathrm{GHz}$ (a frequency inside the notched band), $8 \mathrm{GHz}, \& 9 \mathrm{GHz}$ on both $\mathrm{XY}$ and $\mathrm{XZ}$ planes and Figure 8, Figure 9, Figure 10 \& Figure 11 show their simulated patterns respectively.

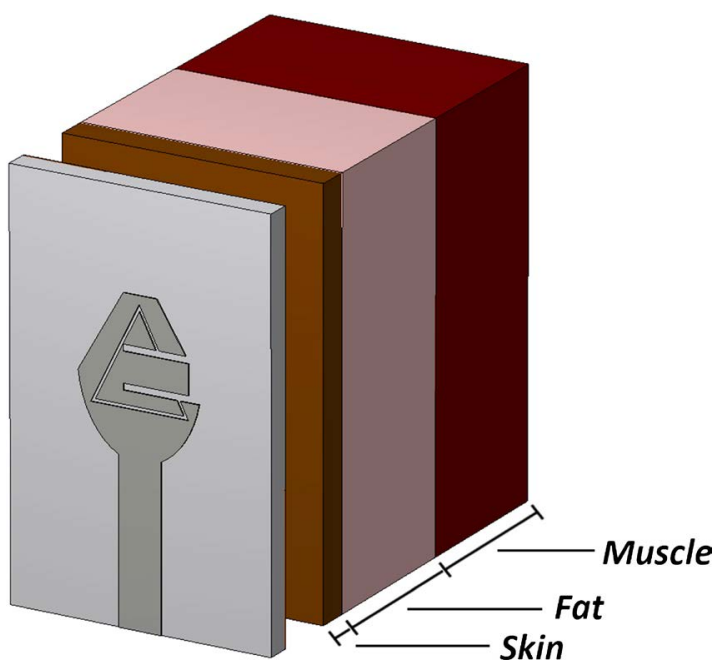

Figure 6. Antenna with 3 layer human body model.

Table 1. Dielectric properties of human body layers.

\begin{tabular}{ccccccc}
\hline \multirow{2}{*}{ Frequency (GHz) } & \multicolumn{3}{c}{ El. Conductivity $(\mathrm{S} / \mathrm{m})$} & \multicolumn{3}{c}{ Rel. Permittivity } \\
\cline { 2 - 7 } & Skin & Fat & Muscle & Skin & Fat & Muscle \\
\hline 3.5 & 2.0249 & 0.15553 & 2.5575 & 37.005 & 5.1739 & 51.444 \\
5.7 & 3.6314 & 0.28663 & 4.8429 & 35.197 & 4.9641 & 48.618 \\
8 & 5.8242 & 0.44301 & 7.7978 & 33.184 & 4.7622 & 45.497 \\
10 & 8.0138 & 0.58521 & 10.626 & 31.29 & 4.6023 & 42.764 \\
\hline
\end{tabular}




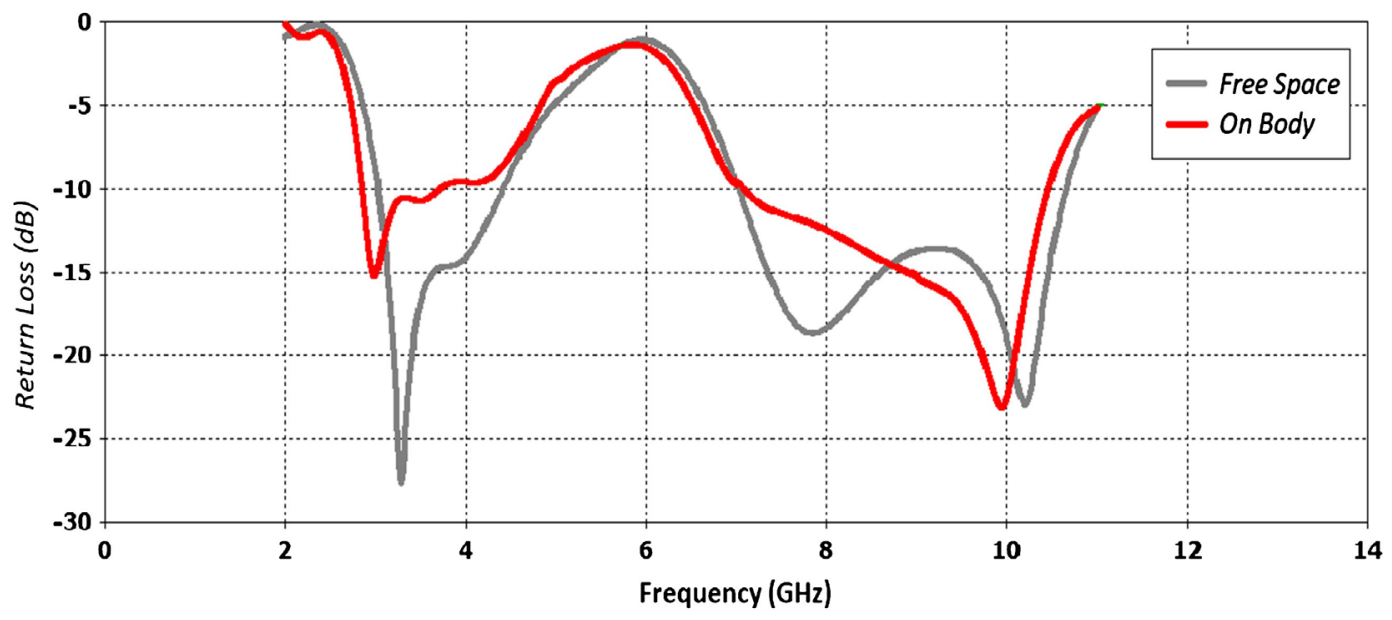

Figure 7. S11 plot comparison.

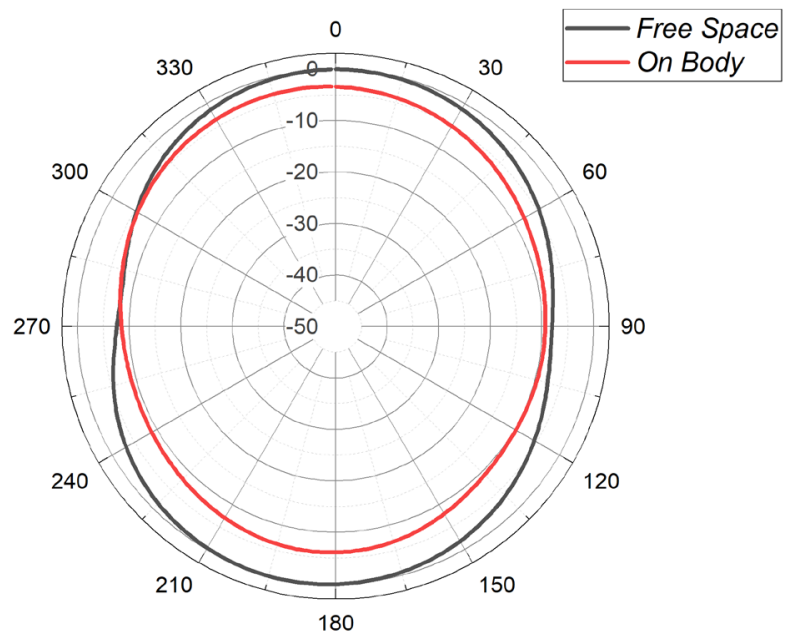

(a)

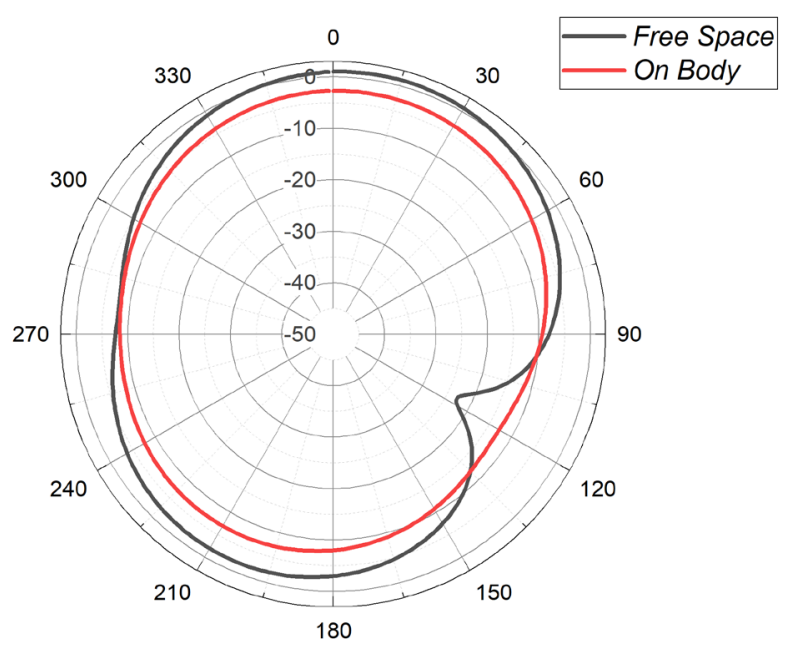

(b)

Figure 8. Radiation pattern comparison at $3.5 \mathrm{GHz}$. (a) On XY Plane; (b) On XZ Plane.

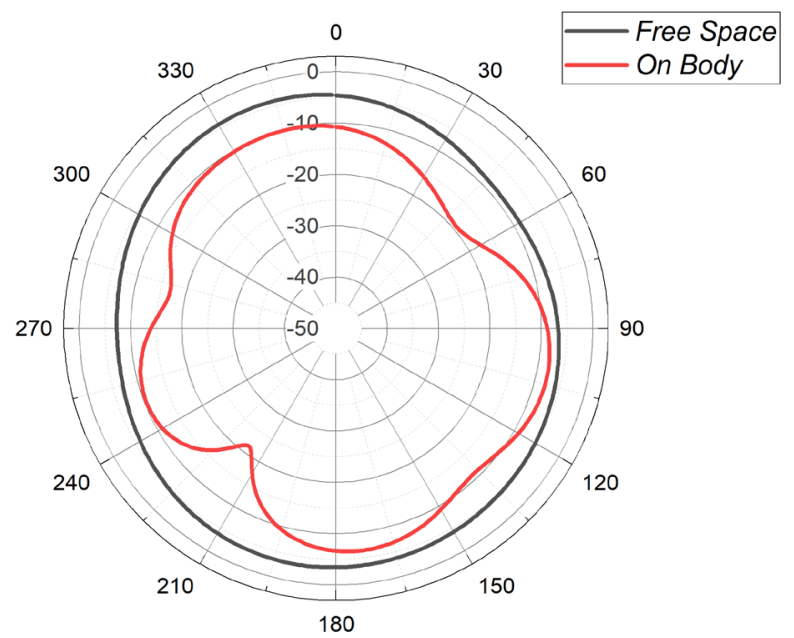

(a)

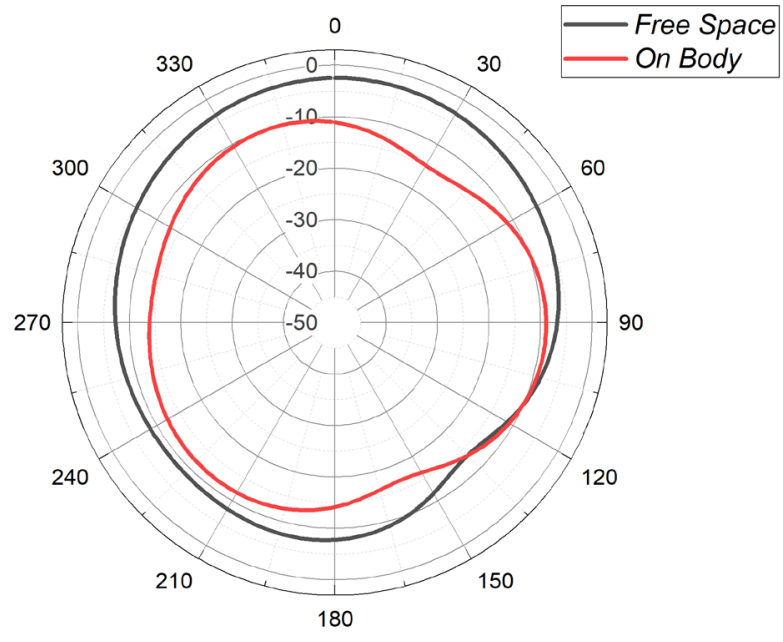

(b)

Figure 9. Radiation pattern comparison at $5.7 \mathrm{GHz}$. (a) On XY Plane; (b) On XZ Plane. 


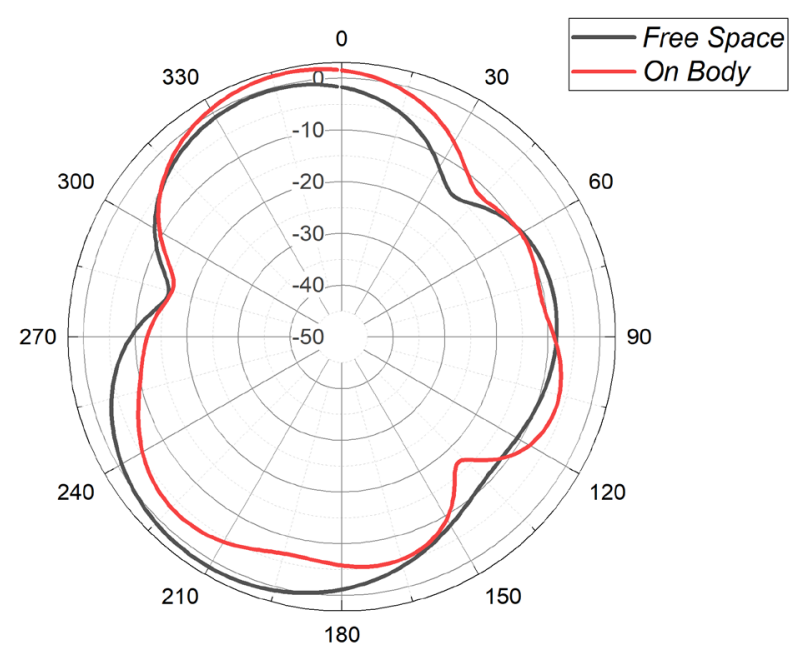

(a)

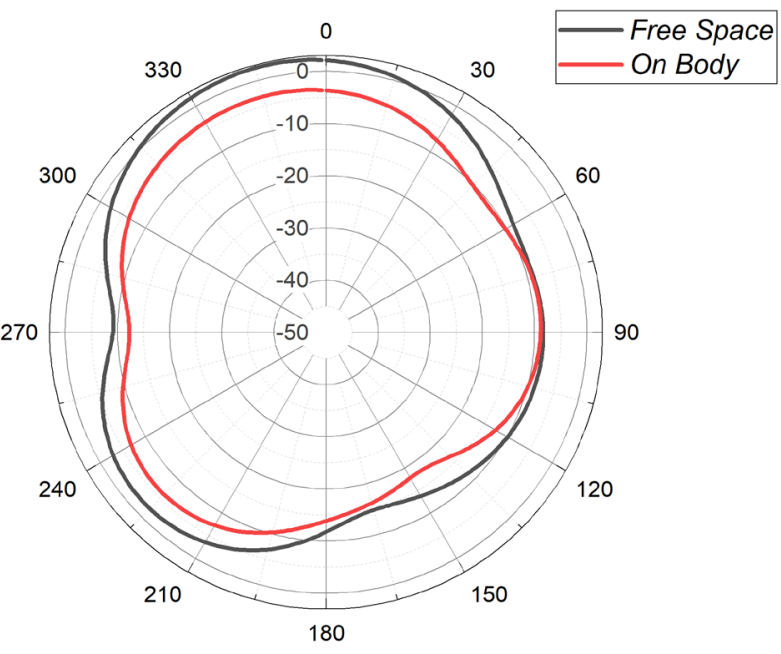

(b)

Figure 10. Radiation pattern comparison at 8 GHz. (a) On XY Plane; (b) On XZ Plane.

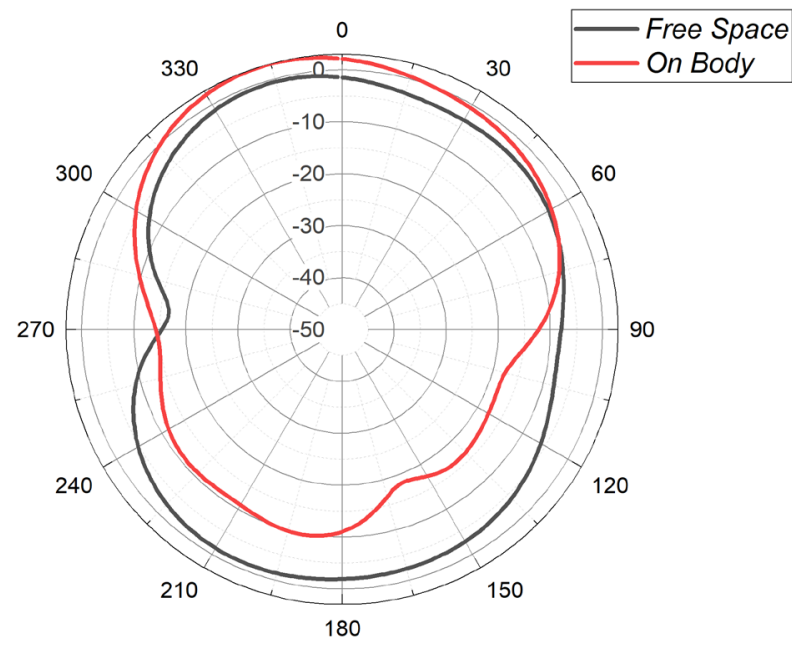

(a)

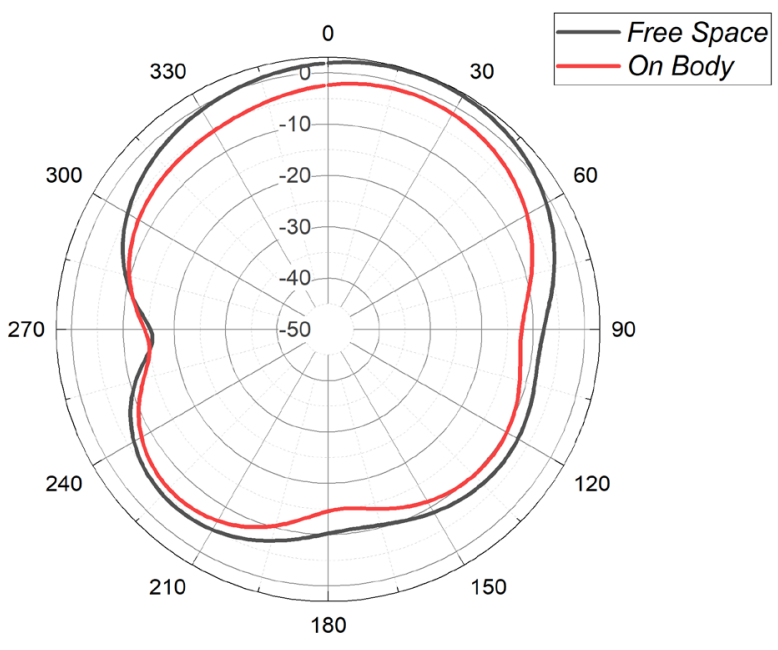

(b)

Figure 11. Radiation pattern comparison at 8 GHz. (a) On XY Plane; (b) On XZ Plane.

Free space patterns from the above figures on different frequencies (i.e. 3.5, 9 $\mathrm{GHz}$ ) exhibits mostly omnidirectional patterns, as the Omni-direction is the best suit for UWB applications, while on-body patterns are very slightly irregular on $\mathrm{XY}$ plane due to the human body placement behind the antenna, which is a natural case. However, the overall patterns for both free space and on-body tests are quite good.

\subsection{Bandwidth}

On body simulation test provides little bit narrower bandwidth than the free space conditions which is visible in Figure 6 plotting. In free space condition, the bandwidth existed almost all the frequencies of UWB's bandwidth (3.1 to 10.6 GHz) except the notched portion in the middle. On-body test exhibits 
slightly different with several bands on 3.2 to $3.8 \mathrm{GHz}$ and 7 to $10.5 \mathrm{GHz}$.

\subsection{Gain}

For On-Body simulation, the antenna was placed in front of the human body three layer model keeping $4 \mathrm{~mm}$ of vacant space. The on-body gain of the proposed UWB antenna shows some differences with the free space simulation as expected. Table 2 shows the comparison of gains on four different frequencies (including a sample frequency of $5.7 \mathrm{GHz}$ inside the notched limit) between free space and On-body simulation.

\subsection{Efficiency}

Both the free space and on-body efficiencies of the proposed antenna are reasonable. More like the other results, on body test produces some loss of efficiency on the simulations but still in a very good acceptable condition. The following Table 3 presents the comparisons between the free space and on-body efficiencies on the notable frequencies.

From the data of Table 2 and Table 3, it is clearly visible that $5.7 \mathrm{GHz}$ displays a poor result in terms of both gain and efficiency, which indicate the effectiveness of the band notch. In addition, the on-body test results are very much stable and similar to the free space on greater frequencies.

\section{Conclusion}

In this paper, a small printed compact UWB band-notched antenna was proposed and its free space and on-body performances were investigated. The antenna was perfectly band notched to avoid interference with other existing networks. Simulated gains were compered and majority of the results shows very much acceptable. We strongly believe that, the antenna can serve perfectly on practical working fields like, healthcare or sports facilities.

\section{Conflicts of Interest}

The authors declare no conflicts of interest regarding the publication of this paper.

Table 2. Gain comparison (dBi).

\begin{tabular}{lcccc}
\hline Frequency & $3.5 \mathrm{GHz}$ & $5.7 \mathrm{GHz}$ & $8 \mathrm{GHz}$ & $10 \mathrm{GHz}$ \\
Free space & 1.168 & -2.445 & 2.802 & 2.706 \\
On-body & -2.236 & -6.338 & 2.576 & 3.435 \\
\hline
\end{tabular}

Table 3. Efficiency comparison.

\begin{tabular}{lllll}
\hline Frequency & $3.5 \mathrm{GHz}$ & $5.7 \mathrm{GHz}$ & $8 \mathrm{GHz}$ & $10 \mathrm{GHz}$ \\
Free space & $85.08 \%$ & $38.25 \%$ & $73.8 \%$ & $78.64 \%$ \\
On-body & $32.82 \%$ & $8.251 \%$ & $43.83 \%$ & $54.76 \%$ \\
\hline
\end{tabular}




\section{References}

[1] Schantz, H.G. (2003) Introduction to Ultra-Wideband Antennas. IEEE Conference on Ultra Wideband Systems and Technologies, 2003, Reston, VA, USA, 16-19 November 2003. https://doi.org/10.1109/UWBST.2003.1267792

[2] Hall, P.S. and Hao, Y. (2012) Antennas and Propagation for Body-Centric Wireless Communications. 2nd Edition, Artech House, London.

[3] Foerester, J., Green, E., Somayazulu, S. and Leeper, D. (2001) Ultrawideband for Short- or Medium-Range Wireless Communications. Intel Technology Journal, $\mathbf{Q}$ $2,11 \mathrm{p}$.

[4] (2008) WSN for Healthcare: A Market Dynamics Report. http://www.onworld.com/healthcare.index.html

[5] Presser, M., Brown, T., Goulianos, A., Stavrou, S. and Tafazolli, R. (2007) Body Centric Context Aware Application Scenarios. 2007 IET Seminar on Antennas and Propagation for Body-Centric Wireless Communications, London, UK, 24 April 2007, 24.

[6] Alomainy, A., Hao, Y., Hu, X., Parini, C.G. and Hall, P.S. (2006) UWB On-Body Radio Propagation and System Modeling for Wireless Body-Centric Networks. IEE Proceedings-Communications, 153, 107-114.

[7] Khan, M.M., Monsurul Alam, A.K.M., Talha, A. and Kumar, P. (2014) Investigation of a Compact Ultrawide Band Antenna for Wearable Applications. International Journal on Communications Antenna and Propagation, 4, 124-129.

[8] Alomainy, A., Sani, A., Rahman, A., Santas, J.G. and Hao, Y. (2009) Transient Characteristics of Wearable Antennas and Radiopropagation Channels for Ultra-Wideband Body Centric Wireless Communications. IEEE Transactions on Antennas and Propagations, 57, 875-884.

[9] See, T.P. and Chen, Z.N. (2009) Experimental Characterization of UWB Antennas for On-Body Communications. IEEE Transactions on Antennas and Propagation, 57, 866-874. https://doi.org/10.1109/TAP.2009.2014595

[10] Klemm, M., Kovacs, I., Pedersen, G. and Toster, G. (2005) Novel Small Size Directional Antenna for UWB WBAN/WPAN Applications. IEEE Transactions on Antennas and Propagation, 53, 3884-3896. https://doi.org/10.1109/TAP.2005.859906

[11] Almpanis, G., Fumeaux, C., Frohlich, J. and Vahldieck, R. (2009) Atruncated Conical Dielectric Resonator Antenna for Body-Areanetwork Applications. IEEE Antennas and Wireless Propagation Letters, 8, 279-282.

[12] Alomainy, A., Hao, Y., Parini, C.G. and Hall, P.S. (2005) Comparison between Two Different Antennas for UWB On-Body Propagation Measurements. IEEE Antennas and Wireless Propagation Letters, 4, 31-34. https://doi.org/10.1109/LAWP.2005.844143

[13] Fedral Communication Commission (2002) First Order and Report: Revision of Part 15 of the Commission's Rules Regarding UWB Transmission Systems.

[14] Liu, H.-W., Ku, C.-H., Wang, T.-S. and Yang, C.-F. (2010) Compact Monopole Antenna with Band-Notched Characteristic for UWB Applications. IEEE Antenna and Wireless Propagation Letters, 9, 397-400.

[15] Jalil, Y.E., Chakrabarty, C.K. and Kasi, B. (2012) A Compact Wideband Microstrip Antenna Integrated with Band-Notched Design. European Journal of Scientific Research, 77, 477-484.

[16] Licul, S., Noronha, J.A.N., Davis, W.A., Sweeney, D.G., Anderson, C.R. and Bielawa, T.M. (2003) A Parametric Study of Time-Domain Characteristics of Possible UWB 
Antenna Architectures. 2003 IEEE 58th Vehicular Technology Conference, Orlando, FL, USA, 6-9 October 2003.

https://doi.org/10.1109/VETECF.2003.1286196

[17] Almpanis, G., Fumeaux, C., Frohlich, J. and Vahldieck, R. (2009) A Truncated Conical Dielectric Resonator Antenna for Body-Area Network Applications. IEEE Antennas and Wireless Propagation Letters, 8, 279-282.

https://doi.org/10.1109/LAWP.2008.2005213

[18] BBC Science \& Nature (2014). http://www.bbc.co.uk/science/humanbody/body/factfiles/skin/skin.shtml

[19] Akkus, O., Oguz, A., Uzunlulu, M. and Kizilgul, M. (2012) Evaluation of Skin and Subcutaneous Adipose Tissue Thickness for Optimal Insulin Injection. Journal of Diabetes \& Metabolism, 3, 216. https://doi.org/10.4172/2155-6156.1000216

[20] Andreuccetti, D., Fossi, R. and Petrucci, C. Calculation of the Dielectric Properties of Body Tissues. Italian National Research Council, IFAC-CNR, Florence, Italy. http://niremf.ifac.cnr.it/tissprop/htmlclie/htmlclie.php 